\title{
Malatya'daki Gökkuşağı Alabalığı (Oncorhynchus mykiss) Kuluçkahanelerinin Yapısal, Biyolojik ve Teknik Yönden İncelenmesi
}

\author{
Murat KARABULUT, Kenan KÖPRÜCÜ* \\ Fırat Üniversitesi Su Ürünleri Fakültesi, 23119 Elazığ, Türkiye
}

\begin{abstract}
$\ddot{O} z$
Bu çalışmada, Malatya'daki gökkuşağı alabalığı (Oncorhynchus mykiss) kuluçkahanelerinin yapısal, biyolojik ve teknik yönleri araştırılmıştır. Gerçek zamanlı olarak işletmelerdeki yetkili kişi ve çalışanlarla yüz yüze yapılan anket çalışmalarıyla veriler elde edilmiştir. Sonuçlara göre, Malatya'daki aktif olarak çalışan yavru gökkuşağı alabalığı kuluçkahanelerinin 5 adeti küçük ( $<2$ milyon adet yavru balık/yıl), 3 adeti orta (2-10 milyon adet yavru balık/yll) ve 2 adeti ise büyük (>10 milyon adet yavru balık/yıl) kapasitelidir. Bu işletmelerin yönetim yapısı \%50 şirket-ortaklık, \%40 şahıs-aile ve $\% 10$ kooperatif şeklindedir. Kü̧̈ük, orta ve büyük ölçekli işletmelerin toplam kapasite içerisindeki payları sırasıyla \%4.18, \%44.15 ve \%51.68 olarak bulunmuştur. Bu kuluçkahanelerin projelendirilmiş toplam kapasitesinin yıllık 52994292 adet yavru balık olduğu belirlenmiştir. Bununla birlikte işletmelere ait yavru balık üretim miktarı yıllık toplam 21514292 adettir. Bu kuluçkahanelerdeki ortalama kapasite kullanım oranı $\% 40.6$ 'dır. Küçük, orta ve büyük ölçekli işletmeler için bu oran sırasıyla $\% 59.85, \% 42.22$ ve \%38.34'dır $(\mathrm{p}<0,05)$. Küçük $(\% 76.7)$ ve orta kapasiteli $(\% 70.2)$ işletmeler, büyük kapasiteli işletmelere (\%63.61) göre daha yüksek üretim verimliliğine sahiptir $(\mathrm{p}<0,05)$. Bu işletmelere ait ortalama üretim verimliliği ise \%74.44 olarak bulunmuştur. Mevcut işletmelerin yapısal, biyolojik ve teknik özelliklerindeki farklılıklar bunların kapasite kullanım oranını ve üretim verimliliğini doğrudan etkilemektedir.
\end{abstract}

Anahtar kelimeler: Malatya, Gökkuşağı alabalığı, Kuluçkahane, Analiz.

\section{Investigation of the Structural, Biological and Technical Aspects of Rainbow Trout (Oncorhynchus mykiss) Hatcheries in Malatya Province}

\begin{abstract}
In this study, the structural, biological and technical aspects of rainbow trout (Oncorhynchus mykiss) hatcheries in Malatya Province were investigated. The raw data of the survey work to be done face to face with the authorized persons and employees in the company has been obtained in real time. According to the results, it was determined that the rainbow trout hatcheries actively working in Malatya Province are five small-sized $(<2$ million fry fish/year), three medium-sized (2-10 million fry fish/year) and two large-sized (>10 million fry fish/year) capacity. The management structure of these companies was 50\% company-partnership, $40 \%$ person-family business and $10 \%$ cooperative. The proportions in the total capacity of the small-scale, medium-scale and large-scale enterprises was found as $4.18 \%, 44.15 \%$ and $51.68 \%$, respectively. Total projected capacity of these hatcheries was determined as 52994292 number fry fish/year. However, the amount of fry rainbow trout production belong to these enterprises was found as 21514292 number fry fish/year. Average capacity usage rate of the hatcheries in Malatya Province was determined as $40.6 \%$. This rate for the small, medium and large-scale hatcheries was calculated as $59.85 \%, 42.22 \%$ and $38.34 \%$, respectively $(\mathrm{p}<0.05)$. The large $(76.7 \%)$ and medium $(70.2)$ scale enterprises have significantly higher $(\mathrm{p}<0.05)$ production efficiency than the small capacity enterprises $(63.61 \%)$. Mean production efficiency value for this enterprises was found as $74.44 \%$. Differences in the structural, biological and technical characteristics of existing enterprises directly affect their capacity usage rate and production efficiency.
\end{abstract}

Keywords: Malatya, Rainbow trout, Hatchery, Analysis.

"Sorumlu yazar: kkoprucu@firat.edu.tr

Geliş Tarihi: 24.07.2018, Kabul Tarihi: 31.10.2018 


\section{Giriş}

Balık kuluçkahanelerinin en önemli amacı, en yüksek oranda ve kalitede yumurta ve yavru balığı en düşük maliyetle üretmektir. Bu durum ise balık kuluçkahanelerinin yapısal sorunlarının belirlenmesi ve çözümlenmesi, anaç stok yönetimi, kuluçkahane ve yavru yönetimi gibi temel üretim ve yetiştiricilik konularına hakim olmakla, teknolojik ve bilimsel uygulamalarla sağlanabilir. Balık kuluçkahanelerinin yapısal özelliklerinin tasarımı, yapımı, biyolojik ve teknik uygulamaların doğru yönetilmesi işletmelerin teknik ve ekonomik sürdürülebilirliği açısından önemlidir $[1,2]$. Ülkemizde bu konu üzerine yapılmış bazı çalışmalar mevcuttur [3-6]. Yetiştiricilik yolu ile yeterli miktarda ve kalitede balık üretilebilmesi yine yeterli sayı ve kalitede yavru balık üretimiyle mümkündür [7]. Malatya ili, su kaynakları bakımından zengin olması ve su ürünleri üretimine uygun bir yap1 göstermesi nedeniyle, balık yetiştiriciliği hızlı bir artış göstermektedir. Özellikle Darende, Doğanşehir, Kale ve Arguvan ilçelerinde gökkuşağı alabalığı (Oncorhynchus mykiss) üreten işletmeler yoğunlaşmaktadır. Bu ilde 2016 yılında, alabalık yetiştiriciliği yapan tesis sayısı 73 adet olup, bunların projelendirilmiş toplam kapasitesi 12228 ton/yıl, gerçekleştirilen üretim miktarı ise 3500 ton/yıl'dır. Bölgedeki su kaynaklarının yeterince kullanılması halinde bu miktarın hızla artabileceği öngörülmektedir [8]. Bu nedenle çalışmada, Malatya' daki gökkuşağı alabalığı kuluçkahanelerinin yapısal, biyolojik ve teknik özellikleri araştırılarak güçlü ve zayıf yönlerinin belirlenmesi amaçlanmıştır.

\section{Materyal ve Metot}

Araştırmanın ana materyalini, Malatya'daki mevcut olan gökkuşağı alabalığı kuluçkahaneleri (toplam 10 adet) oluş̧urmuştur. Malatya'nın Doğanşehir (5 adet) ve Darende (5 adet) ilçelerindeki bu işletmeler yavru balık üretim kapasitelerine göre [8]; yıllık 2 milyon adetten az üretim yapanlar küçük kapasiteli (5 adet), 2-10 milyon adet arasında üretim yapanlar orta kapasiteli (3 adet), 10 milyondan fazla üretim yapanlar ise büyük kapasiteli işletmeler (2 adet) olarak sınıflandırılmıştır. Mevcut işletmelerin yapısal, biyolojik ve teknik özelliklerine ilişkin soruları içeren bir anket hazırlanmıştır [2-4, 6, 9]. Anket (Ek-1), tam sayım yöntemiyle mevcut işletmelerde uygulanmıştır. Alınan bilgilerin yerinde tespiti ve değerlendirilmesi için, 15/01/2016 tarihinden itibaren 1 yıl süresince belirli aralıklarla işletmelere en az $3 \mathrm{kez}$ gidilerek yüz yüze yapılan anket çalışmalarıyla veriler elde edilmiştir. Ayrıca, konu ile ilgili istatistiki verilerden, çeşitli araştıma sonuçlarından, Gıda, Tarım ve Hayvancılık Bakanlığı Malatya İl Müdürlüğü kayıtlarından da faydalanılmıştır.

\subsection{Yapısal parametreler}

\subsubsection{Kuruluş yerinin özellikleri}

İşletmenin alanı, en yakın yerleşim merkezine olan mesafesi, yol ve arazi durumu, işletmenin yapısı ve faaliyet durumu incelenmiştir [1].

\subsubsection{Su kaynağı, havuz, malzeme ve ekipmanların özellikleri}

Kuluçkahanede kullanılan suyun; kaynağ 1 , işletmeye uzaklığı, alınış şekli, kapasite artırmak için yeterliliğii, sıcaklığı, çözünmüş oksijen ve $\mathrm{pH}$ düzeyleri tespit edilmiştir. Suyla ilgili yaşanan sorunlar da belirlenmiştir [6]. Suyun sıcaklığ $1{ }^{\circ} \mathrm{C}$ taksimatlı termometre, çözünmüş oksijen miktarı $(\mathrm{mg} / \mathrm{L})$ portatif oksijen metre ve $\mathrm{pH}$ düzeyi ise portatif $\mathrm{pH}$ metre kullanılarak ölçülmüştür.

İşletmede kullanılan havuzlar; yapı, şekli ve kullanım alanlarına göre incelenmiştir. Çökeltme ve dinlendirme havuzlarının mevcut olup olmadığı tespit edilmiştir. Ayrıca kuluçka dolap ve teknelerinin özellikleri incelenmiştir [2]. 


\subsubsection{Projelendirilmiş kapasite, kapasite kullanım oranı ve üretim verimliliği}

Küçük, orta ve büyük ölçekli işletmelerin proje ve fiili kapasiteleri incelenmiş, kapasite kullanım oranları belirlenmiştir. Ayrıca, mevcut işletmelerin kapasitelerine ve yönetim yapılarına göre verimlilikleri de analiz edilmiştir [3, 6].

\subsubsection{Personel durumu}

İşletmelerde kullanılan aile, daimi ve geçici işgücü; cinsiyet, yaş ve çalışma süreleri dikkate alınarak toplam adam iş gününe çevrilmiştir. Sonra 300 iş gününe bölünerek adam-y1l işçi birimi olarak hesaplanmıştır [10]. İşletmelerdeki işgücü adam-yıl olarak standardize edilmiştir. Aile işgücü potansiyelinin belirlenmesinde Erkek İşgücü Birimi (EİB) esas alınmıştır. EİB, ergin (15-49 yaş arası) bir erkek işçinin günde ortalama 10 saat çalışmasıyla ortaya koyduğu işgücü olarak ifade edilmiştir [11].

\subsection{Biyolojik ve teknik parametreler}

Anaç balıkların sayısı, ağırlıkları, yaşı, yumurta miktarı (adet yumurta/kg balık ağırlığı), yumurta çapı ve temin edildikleri yerlerle ilgili veriler incelenmiştir. Anaç balıklarda birim ağırlık başına düşen yumurta miktarı "Gravimetrik Yöntem" ile belirlenmiştir [7]. Döllenmiş olan yumurtaların çapı ise mm taksimatlı kumpas kullanılarak ölçülmüştür.

Sağım zamanı ve yöntemi, anestezi uygulamasının yapılıp yapılmadığı, yumurtadan çıkış, gözlenme, besin kesesini tüketim süreleri, kuluçkalamada meydana gelen kayıplar, mevsim dışı yumurta alınıp alınmadığı, dişileştirme-erkekleştirme işleminin yapılıp yapılmadığı ve kuluçkalama randımanı belirlenmiştir $[1,12]$.

Anaç ve yavru balıkların beslenmesinde kullanılan yemin markası, cinsi, günlük yem ihtiyacının nasıl belirlendiği, yemin veriliş şekli ve sıklığı araştırılmıştır. Ayrıca, hangi dönemde hastalıkların arttığı, hastalık durumunda alınan tedbirler ve başvurulan yerler, havuzların bakım periyodu ve kullanılan koruyucu maddeler de incelenmiştir [6].

\subsection{Verilerin analizi}

İstatistiksel analizler bilgisayar paket programı (SPSS 23.0)'nda ANOVA ve Duncan testleri kullanılarak yapılmıştır. İstatistiksel önem derecesi \%5 olarak değerlendirilmiştir.

\section{Bulgular ve Tartışma}

\section{1. İşletmelerin yapısal analizi}

\subsubsection{Kuruluş yeri, yol ve arazi özellikleri}

Malatya'daki yavru gökkuşağı alabalığı üreten işletmelerin \%70'inin en yakın yerleşim merkezine uzaklığının 20 km'den az, \%30'unun ise 20-50 km mesafede olduğu tespit edilmiştir (Tablo 1).

Tablo 1. Malatya'daki gökkuşağı alabalığı kuluçkahanelerinin kuruluş yeri özellikleri

\begin{tabular}{|c|c|c|c|c|c|c|c|}
\hline \multirow{2}{*}{$\begin{array}{l}\text { İşletme kapasitesi } \\
\text { (milyon adet } \\
\text { yavru balık/y1l) }\end{array}$} & \multirow[t]{2}{*}{$\begin{array}{l}\text { İşletme sayısı } \\
\text { (adet) }\end{array}$} & \multicolumn{3}{|c|}{$\begin{array}{l}\text { En yakın yerleşim } \\
\text { birimine uzaklığı }(\mathrm{km})\end{array}$} & \multicolumn{3}{|c|}{$\begin{array}{l}\text { Girdi temin } \\
\text { merkezine uzaklığı }(\mathrm{km})\end{array}$} \\
\hline & & $0-20$ & $20-50$ & $50+$ & $0-20$ & $20-50$ & $50+$ \\
\hline Küçük $(<2)$ & 5 & 3 & 2 & - & - & 3 & 2 \\
\hline Orta $(2-10)$ & 3 & 2 & 1 & - & 2 & 1 & - \\
\hline Büyük (>10) & 2 & 2 & - & - & 2 & - & - \\
\hline İl geneli & 10 & $\% 70$ & $\% 30$ & - & $\% 40$ & $\% 40$ & $\% 20$ \\
\hline
\end{tabular}

Kuluçkahanelerin \%40'ının girdi temin merkezine 20 km'den yakın, \%40'ının 20-50 km ve \%20'sinin ise $50 \mathrm{~km}$ 'den daha uzak mesafede olduğu belirlenmiştir. Marmara Bölgesi'nde yapılmış olan bir çalışmada; alabalık işletmelerinin \%96.4'ünün en yakın yerleşim birimine uzaklığının 20 km'den 
daha az, \%3,6'sının 20-50 km arasında değişen bir mesafede olduğu bildirilmiştir [1]. Karadeniz Bölgesi'ndeki alabalık işletmelerinin \%96.1'inin herhangi bir yerleşim merkezine uzaklığının 20 km'den az, \%33.9'unun ise $50 \mathrm{~km}$ 'den daha fazla mesafede olduğu rapor edilmiştir [12]. Akdeniz Bölgesi'nde yapılan bir çalışmada alabalık işletmelerinin \%88'inin herhangi bir yerleşim birimine uzaklığının 20 km'den daha az, \%2'sinin 51 km'den fazla, \%10'unun ise 21-50 km arasında değişen bir mesafede olduğu tespit edilmiştir [13]. Türkiye genelindeki gökkuşağ ${ }_{1}$ alabalığ 1 işletmelerinin $\% 80$ 'i en yakın yerleşim merkezine $20 \mathrm{~km}$ 'den daha az bir uzaklıkta olup, \%20'si 20-50 km arasındadır [1]. Malatya' daki balık kuluçkahanelerinden en yakın yerleşim merkezine uzaklığ $20 \mathrm{~km}$ 'den daha az olanların oranı (\%70); Marmara (\%96.4) [1], Karadeniz (\%96.1) [12] ve Akdeniz (\%88) [13] Bölgeleri ile Türkiye geneli (\%80) [1] için bildirilen oranlardan daha düşük bulunmuştur. Yemin temin edildiği merkezlerin işletmelere uzak oluşu nakliye giderlerini ve dolayısıyla üretim maliyetini artırmaktadır [1].

Malatya'daki yavru gökkuşağı alabalığı üreten işletmelerin \%60'ının asfalt, \%30'unun toprak ve \%10'unun ise stabilize yola sahip olduğu belirlenmiștir (Tablo 2). Bunların \%50'sinin vadi arasında, $\% 40$ 'ının açık arazide ve \%10'unun dağ eteğinde kurulduğu görülmüştür.

Tablo 2. Malatya'daki gökkuşağı alabalığı kuluçkahanelerinin yol ve arazi durumu

\begin{tabular}{|c|c|c|c|c|c|c|c|}
\hline \multirow{2}{*}{$\begin{array}{l}\text { İşletme kapasitesi } \\
\text { (milyon adet } \\
\text { yavru balık/yıl) }\end{array}$} & \multirow{2}{*}{$\begin{array}{l}\text { İşletme } \\
\text { sayısı } \\
\text { (adet) }\end{array}$} & \multicolumn{3}{|c|}{ Yol durumu } & \multicolumn{3}{|c|}{ Arazi durumu } \\
\hline & & Asfalt & Stabilize & Toprak & $\begin{array}{l}\text { Vadi } \\
\text { arası }\end{array}$ & $\begin{array}{l}\text { Dağ } \\
\text { eteği }\end{array}$ & $\begin{array}{l}\text { Açık } \\
\text { arazi }\end{array}$ \\
\hline Küçük $(<2)$ & 5 & 3 & 1 & 1 & 3 & 1 & 1 \\
\hline Orta (2-10) & 3 & 1 & - & 2 & 2 & - & 1 \\
\hline Büyük (>10) & 2 & 2 & - & - & - & - & 2 \\
\hline İl geneli & 10 & $\% 60$ & $\% 10$ & $\% 30$ & $\% 50$ & $\% 10$ & $\% 40$ \\
\hline
\end{tabular}

Samsun'daki alabalık işletmelerinin; \%20'si vadi arasında, \%40'ı dağ eteğinde ve \%40'1 ise açık arazide kurulmuştur [4]. Akdeniz Bölgesi'ndeki alabalık işletmelerinin; \%68.2'si asfalt, \%21.7'si stabilize ve \%10.1'i toprak yola sahiptir [13]. Erzurum'daki alabalık işletmelerin; \%81'i vadi arasında, $\% 14.2$ 'si dağ eteğinde ve \%4.8'i açık arazidedir [14]. Belirtilen çalışmalardaki işletmelerin arazideki konumları genellikle bulundukları bölgenin coğrafik yapısıyla ve su kaynağına yakınlığıyla doğrudan ilişkilidir.

\subsection{2. İşletmelerde kullanılan su, havuz, alet ve ekipmanlar}

Kuluçkahanelerde kullanılan suyun sıcaklığının $10-13{ }^{\circ} \mathrm{C}$, çözünmüş oksijen düzeyinin $6.5-9 \mathrm{mg} / \mathrm{L}$ ve pH değerinin ise 7-8 aralığında değiştiği tespit edilmiştir (Tablo 3). İşletmelerin \%80'inin kaynak suyunu, \%20'sinin ise akarsuyu kullandığı saptanmıştır. Gümüş ve Şahin [15], Antalya ilindeki yavru gökkuşağı alabalı̆̆ 1 üreten kuluçkahanelerin \%91.4'ünün kaynak suyu kullandığını ve mevcut işletmelerin \%45.8'inde kullanılan suyun sıcaklığının $10{ }^{\circ} \mathrm{C}$ 'nin altında olduğunu bildirmişlerdir. Mevcut durum gökkuşağı alabalığı kuluçkahanelerinde ağılıklı bir şekilde kaynak suyu kullanıldığını göstermektedir.

Tablo 3. Kuluçkahanelerde kullanılan suya ait sıcaklık, çözünmüş oksijen ve pH değerleri

\begin{tabular}{lllll}
\hline $\begin{array}{l}\text { İşletme kapasitesi } \\
\text { (milyon adet yavru balık/yıl) }\end{array}$ & $\begin{array}{l}\text { İşletme } \\
\text { sayısı (adet) }\end{array}$ & $\begin{array}{l}\text { Sıcaklık } \\
\left({ }^{\circ} \mathrm{C}\right)\end{array}$ & $\begin{array}{l}\text { Çözünmüs } \\
\text { oksijen }(\mathrm{mg} / \mathrm{L})\end{array}$ & pH \\
\hline Küçük $(<2)$ & 5 & $12.00 \pm 1.00^{\mathrm{c}}$ & $8.00 \pm 1.00^{\mathrm{b}}$ & $7.75 \pm 0.25$ \\
Orta $(2-10)$ & 3 & $11.00 \pm 0.50^{\mathrm{b}}$ & $7.75 \pm 1.25^{\mathrm{b}}$ & $7.50 \pm 0.50$ \\
Büyük $(>10)$ & 2 & $10.50 \pm 0.50^{\mathrm{a}}$ & $7.00 \pm 0.50^{\mathrm{a}}$ & $7.50 \pm 0.50$ \\
\hline
\end{tabular}

${ }^{*}$ Aynı sütundaki farklı harflerle $(\mathrm{a}, \mathrm{b}, \mathrm{c})$ gösterilen değerler arasındaki farklılıklar önemlidir $(\mathrm{p}<0,05)$

Malatya'daki işletmelerde genellikle dikdörtgen şeklinde, betondan yapılmış olan yavru ve anaç balık havuzlarının mevcut olduğu görülmüştür. Yavru balıklar için kullanılan fiberglas teknelerin yuvarlak veya dikdörtgen şeklinde olduğu belirlenmiştir. Üretimde yaygın olarak dikey kuluçka dolabı kullanılmakla birlikte, tekne tipi kuluçkalama araçlarından da yararlanıldığı tespit edilmiştir. Gümüş ve Şahin [15]'e göre, Antalya'daki gökkuşağı alabalığı kuluçkahanelerinin \%68.6's1 yumurta inkübasyonunda dikey kuluçka dolabı kullanmaktadır. Bu durum, döllenmiş balık yumurtalarının 
kuluçkalanması işlemlerinde ülkemizdeki alt yapının nispeten güçlü olduğunu, mevcut alanın ve suyun en verimli şekilde değerlendirilmesine imkan sağlayan donanımların kullanıldığını göstermektedir.

\subsection{3. İşletme alanı}

Malatya'daki yavru gökkuşağı alabalığı üreten küçük, orta ve büyük ölçekli işletmelerin sırasıyla 64 000, 27700 ve $23000 \mathrm{~m}^{2}$ toplam alana sahip olduğu belirlenmiştir. Bu işletmelerde kuluçkahaneye ayrılan ortalama alannın sırasıyla; 500,650 ve $600 \mathrm{~m}^{2}$, kuluçkahanelerin toplam alan içerisindeki oranlarının ise sırasıyla; \%0.78, \%2.34 ve \%2.60 olduğu hesaplanmıştır $(\mathrm{p}<0,05)$. İşletmelerin üretken alanının toplam alan içerisindeki ortalama payının \%1.52 olduğu tespit edilmiştir (Tablo 4). Bu oran mevcut işletmelerin toplam ve üretken alanlarını verimli bir şekilde kullanamadığını göstermiştir.

Tablo 4. Malatya'daki gökkuşağı alabalığı kuluçkahanelerinin alan kullanım oranları

\begin{tabular}{lllll}
\hline $\begin{array}{l}\text { İşletme kapasitesi } \\
\text { (milyon adet yavru balık/yıl) }\end{array}$ & $\begin{array}{l}\text { Isşletme sayıs } \\
(\text { adet })\end{array}$ & $\begin{array}{l}\text { Toplam alan } \\
\left(\mathrm{m}^{2}\right)\end{array}$ & $\begin{array}{l}\text { Kuluçkahane alanı } \\
\left(\mathrm{m}^{2}\right)\end{array}$ & $\begin{array}{l}\text { Alan kullanım } \\
\text { oranı }\end{array}$ \\
\hline Küçük $(<2)$ & 5 & $64000^{\mathrm{c}}$ & $500^{\mathrm{a}}$ & $0.78^{\mathrm{a}}$ \\
Orta $(2-10)$ & 3 & $27700^{\mathrm{b}}$ & $650^{\mathrm{c}}$ & $2.34^{\mathrm{b}}$ \\
Büyük $(>10)$ & 2 & $23000^{\mathrm{a}}$ & $600^{\mathrm{b}}$ & $2.60^{\mathrm{c}}$ \\
\hline İl geneli & 10 & 114700 & 1750 & 1.52 \\
\hline *Aynı sütundaki farklı harflerle (a, b, c) gösterilen değerler arasındaki farklılıklar önemlidir $(\mathrm{p}<0,05)$
\end{tabular}

\subsubsection{Kapasite kullanım oranı}

Malatya' daki yavru gökkuşağı alabalığ olduğu, bu oranın küçük (\%59.85), orta (\%42.22) ve büyük (\%38.34) ölçekli işletmelerde istatistiksel olarak önemli $(\mathrm{p}<0,05)$ farklılıklar gösterdiği (Tablo 5) tespit edilmiştir. Küçük işletmelerin, orta ve büyük ölçekli olanlara göre daha yüksek kapasite kullanım oranına sahip olduğu belirlenmiştir $(p<0,05)$.

Tablo 5. Malatya'daki alabalık kuluçkahanelerinin kapasite kullanım oranları

\begin{tabular}{|c|c|c|c|c|c|c|}
\hline \multirow{2}{*}{$\begin{array}{l}\text { İşletme kapasitesi } \\
\text { (milyon adet } \\
\text { yavru balık/yıl) }\end{array}$} & \multicolumn{2}{|c|}{ İşletme sayısı } & \multicolumn{2}{|c|}{ Proje kapasitesi } & \multirow{2}{*}{$\begin{array}{l}\text { Kullanılan } \\
\text { kapasite (adet } \\
\text { yavru balık/yıl) }\end{array}$} & \multirow{2}{*}{ 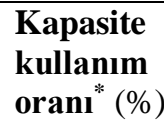 } \\
\hline & adet & $\%$ & $\begin{array}{l}\text { adet yavru } \\
\text { balık/yıl }\end{array}$ & $\%$ & & \\
\hline Küçük (<2) & 5 & 50 & 1494292 & 2.8 & 894292 & $59.85^{\mathrm{c}}$ \\
\hline Orta $(2-10)$ & 3 & 30 & 22500000 & 42.5 & 9500000 & $42.22^{b}$ \\
\hline Büyük (>10) & 2 & 20 & 29000000 & 54.7 & 11120000 & $38.34^{\mathrm{a}}$ \\
\hline İl geneli & 10 & 100 & 52994292 & 100 & 21514292 & 40.60 \\
\hline
\end{tabular}

$\mathrm{Bu}$ sonuçlar, Malatya'daki mevcut işletmelere ait kapasite kullanım oranlarının çok düşük olduğunu, projelendirilmiş üretim kapasitelerine ulaşılamadığını göstermiştir. Bunun nedeni; işletmelerin gerçek üretim kapasitelerinin projelendirme safhasında doğru hesaplanmamasına veya alt yapı eksikliğine, teknik ve mali yetersizliklere bağlanmıştır.

\subsection{5. Üretim miktarına göre işletmelerin verimliliği}

İşletmelerin üretim miktarına göre verimliliği incelendiğinde (Tablo 6); en yüksek verimliliğe büyük ölçekli işletmelerin sahip olduğu (\%76.7), bunu orta (\%70.2) ve küçük (\%63.61) ölçekli olanların takip ettiği görülmüştür $(p<0,05)$. Mevcut işletmelerin ortalama üretim verimliliğinin ise \%74.44 olduğu hesaplanmıştır. Bu oran, mevcut işletmelerin üretim verimliliğinin düşük olduğunu göstermiştir. Bunun nedeni; işletmelerin kuluçkahane yönetimi hakkında yetersiz bilgiye sahip olmasına, biyoteknolojik uygulamaların yapılmamasına, yumurtaların döllenmesi ve yavru balıkların büyütülmesi aşamalarından meydana gelen kayıpların fazla olmasına, yeterli donanıma sahip kalifiye elamanların çalıştırılmamasına, sermaye ve alt yapı yetersizliğine bağlanmıştır. 
Tablo 6. Malatya' daki alabalık kuluçkahanelerinin üretim miktarına göre verimliliği

\begin{tabular}{|c|c|c|c|c|}
\hline $\begin{array}{l}\text { İşletme kapasitesi } \\
\text { (milyon adet } \\
\text { yavru balık/yıl) }\end{array}$ & $\begin{array}{l}\text { İşletme } \\
\text { sayısı } \\
\text { (adet) }\end{array}$ & $\begin{array}{l}\text { Üretimde kullanılan } \\
\text { yumurta miktarı } \\
\text { (adet yumurta/yıl) }\end{array}$ & $\begin{array}{l}\text { Yavru balık üretimi } \\
\text { (adet yavru balık/yıl) }\end{array}$ & $\begin{array}{l}\text { Üretim } \\
\text { verimliliği* } \\
(\%)\end{array}$ \\
\hline Küçük $(<2)$ & 5 & $1450000^{\mathrm{a}}$ & $894292^{a}$ & $63.61^{\mathrm{a}}$ \\
\hline Orta $(2-10)$ & 3 & $12950000^{\mathrm{b}}$ & $9500000^{\mathrm{b}}$ & $70.20^{\mathrm{b}}$ \\
\hline Büyük (>10) & 2 & $14500000^{\mathrm{c}}$ & $11120000^{\mathrm{c}}$ & $76.70^{\mathrm{c}}$ \\
\hline İl geneli & 10 & 28900000 & 21514292 & 74.44 \\
\hline
\end{tabular}

*Aynı sütundaki farklı harflerle $(a, b, c)$ gösterilen değerler arasındaki farklılıklar önemlidir $(\mathrm{p}<0,05)$

\subsubsection{Yönetim yapısına göre işletmelerin verimliliği}

Mevcut işletmelerin \%50'sinin yapısının şirket-ortaklık şeklinde olduğu belirlenmiştir. Bunların yavru balık üretim kapasitelerinin yıllık 29220000 adet, toplam kapasite içerisindeki payının ise \%55.13 olduğu tespit edilmiştir. Şahıs-aile işletmelerinin oranı \%40 olarak hesaplanmıştır. Bunların yavru balık üretim kapasitelerinin yıllık 23174292 adet, toplam kapasite içerisindeki payının ise \%43.72 olduğu belirlenmiştir. İşletmelerin \%10'unun yapısının kooperatif şeklinde olduğu görülmüştür. Bunların yavru balık üretim kapasitelerinin yıllık 600000 adet ve toplam kapasite içerisindeki payının ise \%1.15 olduğu hesaplanmıştır (Tablo 7). Şirket-ortaklık işletmelerinin en yüksek verimlilik oranına (\%50.79) sahip olduğu görülmüştür. Bunu sırasıyla kooperatif $(\% 50)$ ve şahıs-aile $(\% 27.5)$ işletmelerinin takip ettiği saptanmışır $(\mathrm{p}<0,05)$.

Tablo 7. Malatya'daki alabalık kuluçkahanelerinin yönetim yapısına göre verimliliği

\begin{tabular}{|c|c|c|c|c|c|c|}
\hline \multirow[t]{2}{*}{$\begin{array}{l}\text { İşletmenin } \\
\text { yönetim yapısı }\end{array}$} & \multicolumn{2}{|c|}{$\begin{array}{l}\text { İşletme } \\
\text { sayısı }\end{array}$} & \multicolumn{2}{|c|}{$\begin{array}{l}\text { Proje kapasitesi } \\
\text { (yavru balık) }\end{array}$} & \multirow[t]{2}{*}{$\begin{array}{l}\text { Kullanılan kapasite } \\
\text { (adet yavru balık/yıl) }\end{array}$} & \multirow{2}{*}{$\begin{array}{l}\text { Üretim } \\
\text { verimliliği* } \\
(\%)\end{array}$} \\
\hline & adet & $\%$ & adet/y1l & $\%$ & & \\
\hline Şirket-ortaklık & 5 & 50 & $29220000^{\mathrm{c}}$ & $55.13^{c}$ & $14840000^{\mathrm{c}}$ & $50.79^{\mathrm{b}}$ \\
\hline Şahıs-aile & 4 & 40 & $23174292^{b}$ & $43.72^{b}$ & $6374292^{b}$ & $27.50^{\mathrm{a}}$ \\
\hline Kooperatif & 1 & 10 & $600000^{a}$ & $1.15^{\mathrm{a}}$ & $300000^{a}$ & $50.00^{b}$ \\
\hline
\end{tabular}

${ }^{*}$ Aynı sütundaki farklı harflerle $(a, b, c)$ gösterilen değerler arasındaki farklılıklar önemlidir $(p<0,05)$

Marmara Bölgesi'ndeki alabalık işletmelerinin; \%74.5'i şahıs, \%21.5'i şirket, \%2'si kooperatif ve \%2'si kamu işletmesidir [3]. Antalya'daki alabalık işletmelerinin; \%62.4'ü şahıs-aile, \%34.4'ü şirketortaklık ve \%3.2'si ise kamu işletmesi şeklindedir [5, 16]. Marmara Bölgesi ve Antalya'daki alabalık işletmelerinin çoğunluğu şahıs-aile işletmeleri iken, Malatya'dakilerin önemli bölümünü şirket-ortaklık işletmeleri $(\% 50)$ oluşturmuştur.

\subsubsection{Personel durumu}

Malatya' daki gökkuşağı alabalığ kuluçkahanelerinde toplam 21 kişinin istihdam edildiği belirlenmiştir. $\mathrm{Bu}$ işletmelerin \%40'ında 1, \%30'unda 2 ve \%20'sinde ise 3 kişinin çalıştırıldığ 1 tespit edilmiştir. Marmara Bölgesi'ndeki alabalık işletmelerinin \%52.9'unda 1-3 arasında işçi çalıştırıldığı bildirilmişdir [17]. Balık kuluçkahanelerinde yüksek işgücüne ihtiyaç duyulmaktadır. İşletmelerin kapasitesi arttıkça çalışan personele olan ihtiyaç da artmıştır.

Malatya'daki yavru alabalık üreten işletmelerde çalışan personelin mesleki tecrübesi incelendiğinde; çalışma süresi 1-5 yıl arasında olanların \%28.6, 6-10 yıl olanların \%42.85, 11-15 yıl olanların \%23.8, 16 yıl ve üzeri olanların ise \%4.75 oranında olduğu görülmüştür. Antalya' daki alabalık işletmelerinde çalışanların; \%46.6'sı 10 yıldan az, \%39.7'si 11-20 yıl arasında, \%13.7'si 21 yıldan fazla mesleki tecrübeye sahiptir [5]. Elazığ'daki alabalık işletmelerinde çalışan personelin; \%54.17'sinin mesleki tecrübesi 1-5 y1l, \%28.86'sinın 6-10 yıl, \%13.95'inin 11-15 y1l, \%3.01'inin ise 16 yıl veya üzerindedir [6]. Genel olarak mevcut işletmelerde çalışan personelin mesleki tecrübelerinin düşük olduğu görülmektedir.

Personelin mesleki niteliği ve yaş durumu incelendiğinde; Malatya'daki alabalık kuluçkahanelerinde çalışanların \% 14.28 'inin mühendis ve \%85.72'sinin ise vasıfsız işçilerden oluştuğu görülmüştür. Bu işletmelerde çalışan teknik eleman bulunmamaktadır. Mevcut personelin tamamı erkek 
olup, bunların büyük çoğunluğu 15-49 yaş aralığındadır. Antalya'daki alabalık işletmelerinde çalışan personelin; \%60.2'si işçi, \%32.9'u işveren (aile bireyi) ve \%6.9'u mühendis olup, bunların \%91.8'i erkek, \%8.2'si kadınlardan oluşmaktadır [5]. Marmara Bölgesi'ndeki alabalık işletmelerinde çalı̧̧an personelin; \%31.1'inin aile bireylerinden, \%33.8'inin vasıfsız işçilerden, \%25.6'sının eğitilmiş işçilerden, \%6.1'inin mühendislerden ve \%3.4'ünün teknik elemanlardan oluşmaktadır. Bunların \%86.5'i erkek, \%13.5'i ise kadındır. Personelin yaşları 19-70 arasında değişmekte olup, \%29.1'i 30-39 yaş, \%23'ü 39-49 yaş aralığındadır [17]. Belirtilen işletmelerde çalışan personelin cinsiyet ve yaş dağılım oranları coğrafik bölgelere göre değişiklik göstermektedir. Balık yetiştiriciliği kaba iş gücüne dayalı olduğundan genellikle erkekler tarafından tercih edilmektedir. Bu durum, mevcut işletmelerde çalışan kadın personel oranının düşük seviyede olmasını açıklamaktadır.

\section{2. İşletmelerin biyolojik ve teknik analizi}

Malatya'daki yavru gökkuşağı alabalığı üreten kuluçkahanelerin tamamında elle sağım işlemi yapıldığı ve yumurtaların döllenmesinde kuru yöntemin uygulandığı tespit edilmiştir. Küçük işletmeler KasımAralık aylarında, orta ve büyük ölçekli işletmeler ise Kasım-Şubat aylarında sağım işlemini gerçekleştirmektedir. Küçük işletmelerin $\% 60$ ' 1 , orta işletmelerin $\% 67$ 'si ve büyük işletmelerin $\% 50$ 'si sağımdan sonra balıklarda yumurta kontrolü yapmaktadır (Tablo 8). Küçük ölçekli olan 2 adet kuluçkahane hariç, diğerlerinin tümünde sağım işlemi öncesinde balıklara anestezi uygulanmaktadır. Anestezik madde olarak MS222, benzocaine, fenossietenol, karanfil yağ 1 gibi maddeler kullanılmaktadır. Mevcut işletmelerde üretilen balıklarda dişileştirme veya erkekleştirme gibi biyoteknolojik uygulamalar yapılmamaktadır. Kuluçkahanelerde döllenmiş yumurtaların gözlenme süresi 14-17 gün, açılma süresi 28-32 gün arasında değişmekte olup, ortalama kuluçka randımanı \%85 düzeyindedir. İşletmelerin tamamı yavru balık üretiminde kendi bünyesinde bulunan anaç balıkları kullanmaktadır. Anaç balıkların ağırlı̆̆ 1-6 kg, yaşı ise 2-6 yaş arasında değişmektedir. Dişi anaç balıklardan $\mathrm{kg}$ ağırlık başına 1000-3000 adet arasında yumurta (3-5 mm çapında) alınmaktadır.

Gümüş ve Şahin [15]'e göre, Antalya'daki gökkuşağ a alabalığı üreticilerinin \%61.4'ü yumurta ve yavru balık ihtiyacını kendi işletmelerinde üretim yaparak karşılarken, \%25'i üretim ile birlikte satın alma ve \%13.6'sı ise sadece satın alarak ihtiyacını karşılamaktadır. İşletmelerin \%54.3'ünde yumurta gözlenme ve açılım oranı \%80'den daha düşüktür.

Tablo 8. Malatya'daki gökkuşağı alabalığı kuluçkahanelerinin sağım özellikleri

\begin{tabular}{|c|c|c|c|c|c|c|}
\hline $\begin{array}{l}\text { İşletme kapasitesi } \\
\text { (milyon adet } \\
\text { yavru balık/yıl) }\end{array}$ & $\begin{array}{l}\text { İşletme } \\
\text { sayısı } \\
\text { (adet) }\end{array}$ & $\begin{array}{l}\text { Sağım } \\
\text { zamanı }\end{array}$ & $\begin{array}{l}\text { Sağım } \\
\text { şekli }\end{array}$ & $\begin{array}{l}\text { Yumurta } \\
\text { kontrolü } \\
(\%)\end{array}$ & $\begin{array}{l}\text { Anestezi } \\
\text { uygulaması } \\
(\%)\end{array}$ & $\begin{array}{l}\text { Yumurtayı } \\
\text { dölleme } \\
\text { şekli }\end{array}$ \\
\hline Küçük $(<2)$ & 5 & Kasım-Aralık & Elle & $60^{b}$ & $40^{\mathrm{a}}$ & Kuru yöntem \\
\hline Orta $(2-10)$ & 3 & Kasım-Şubat & Elle & $67^{c}$ & $100^{\mathrm{b}}$ & Kuru yöntem \\
\hline Büyük (>10) & 2 & Kasım-Şubat & Elle & $50^{\mathrm{a}}$ & $100^{\mathrm{b}}$ & Kuru yöntem \\
\hline
\end{tabular}

${ }^{*}$ Aynı sütundaki farklı harflerle $(a, b, c)$ gösterilen değerler arasındaki farklılıklar önemlidir $(p<0,05)$

Malatyadaki işletmelerde üretilen yavru balıklar 1-7 g ve 7-50 g ağırlığında iken hastalık görülmektedir. Bu hastalıklardan meydana gelen kayıplar bazı işletmelerde \%80'lere ulaşmaktadır. Ortaya çıkan hastalıklara karşı alınan önlemler kulaktan dolma ve eski usuldür. Hastalık etkenlerinin araştırılması ve koruyucu tedbirlerin alınması işletmelerin verimliliği ve karlılığı açısından büyük önem taşımaktadır. Tedavi amacıyla yapılan işlemler yetersizdir. Bu nedenle, balık hastalıkları konusunda uzmanlaşmış birimlerin desteğine ihtiyaç duyulmaktadır. Bu durum ülkemizin diğer bölgeleri için de benzerlik göstermektedir. Gümüş ve Şahin [15]'e göre, Antalya'daki gökkuşağı alabalığı işletmelerinde hastalık görülme durumu \%70 ile 0.3-5 g ağırlığındaki balıklarda en yüksek orandadır. İşletmelerin \%76.9'unda yavru balıkların yaşama oranı \%80'den daha düşüktür. Antalya'daki işletmelerin \%48'i hastalık problemini kendisi çözümlemeye çalışmaktadır.

Malatya'daki mevcut işletmelerin tümünde karma yem kullanılmaktadır. İşletmelerin çoğu "Su Ürünleri Kooperatifinden" alabalık yemi temin etmektedir. Genellikle yemin fiyatı, temin edebilirliği bu tercihte rol oynamaktadır. Diğer işletmelerde kullanılan yemlerin performansı veya bu yemlerden kaynaklanan sorunlar da yem tercihinde dikkate alınmaktadır. İşletmelerin \%80'i iki farklı firmaya ait yemi kullanmakta, \%20'si ise çeşitli markalara ait yemleri değerlendirmektedir. İşletmelerin tamamında 
yemleme elle yapılmaktadır. Balıklara verilen yem miktarı ve öğün sayısı su sıcaklığı ve balık büyüklüğüne göre ayarlanmaktadır.

\section{Sonuç ve Öneriler}

Malatya'daki yavru gökkuşağı alabalığı üreten işletmelerde tam sayım yöntemiyle yapılan anket sonuçlarına göre; mevcut işletmelerin arazideki konumları bölgenin coğrafik yapısıyla ve su kaynağına yakınlığıyla doğrudan ilişkilidir. Yemin temin edildiği merkezlerin işletmelere uzak oluşu nakliye giderlerini ve dolayısıyla üretim maliyetini artırmaktadır. Bu işletmelerde toplam ve üretken alanların verimli bir şekilde kullanılamadığı, kapasite kullanım oranlarının çok düşük olduğu ve projelendirilmiş üretim kapasitelerine ulaşılamadığı görülmüştür. İşletmelerde hastalık nedeniyle büyük kayıplar meydana gelmektedir. Tedavi amacıyla yapılan işlemler yetersizdir. Hastalık etkenlerinin araştırılması ve koruyucu tedbirlerin alınması işletmelerin verimliliği ve karlılığı açısından büyük önem taşımaktadır. $\mathrm{Bu}$ nedenle, balık hastalıkları konusunda uzmanlaşmış birimlerin desteğine ihtiyaç duyulmaktadır. Mevcut işletmeler genelde küçük aile tipi işletmeleridir. Bunların büyük bölümü maddi imkânsızlıklardan dolayı uygun olmayan şartlarda üretim yapmaktadır. Ekonomik durumu iyi olan işletmeler ise yeterli teknolojiyi kullanacak yetişmiş elaman istihdam etmediklerinden dolay1, olması gereken üretim verimliliğine sahip değildir. Bununla birlikte, küçük (\%76.7) ve orta ölçekli (\%70.2) işletmelerin üretim verimliliği, büyük kapasiteli olanlara (\%63.61) göre daha yüksektir. Malatya'daki yavru gökkuşağı alabalığı üretiminin ve kalitesinin arttırılabilmesi için; bazı işletmeler teşvik edilerek sadece yavru balık üretimine yönlendirilmelidir. Yavru balık üreticilerinin örgütlenmesi ve teknolojik alt yapılarının geliştirilebilmesi için bölgedeki hibe fonlarından faydalanmaları sağlanmalıdır.

\section{Teșekkür}

Bu çalışma, Fırat Üniversitesi Bilimsel Araştırma Projeleri (FÜBAP) Koordinasyon Birimi tarafından desteklenen proje (SÜF.14.07) kapsamında gerçekleştirilmiş olup, birinci yazarın yüksek lisans tezinden özetlenmiştir.

\section{Kaynaklar}

[1] Rad F., Köksal G. 2001. Türkiye'deki Gökkuşağı Alabalığı (Oncorhynchus mykiss) İşletmelerinin Yapısal ve Biyo-Teknik Analizi, Turkish Journal of Veterinary \& Animal Sciences, 25: 567-575.

[2] Karataş M., Sayılı M., Koç B. 2008. Sivas İli Gökkuşağı Alabalığ1 İşletmelerinin Yapısal ve Ekonomik Analizi, Biyoloji Bilimleri Araştırma Dergisi (BİBAD), 1 (2): 55-61.

[3] Yıldız M., Doğan K., Ener E. 2008. Marmara Bölgesi Gökkuşağı Alabalığı (Oncorhynchus mykiss) İşletmelerinin Yapısal, Teknolojik ve Verimlilik Analizleri, İstanbul Üniversitesi Su Ürünleri Dergisi, 23: 1-16.

[4] Aydın O., Sayılı M. 2009. Samsun İlindeki Alabalık İşletmelerinin Yapısal ve Ekonomik Analizi, Gaziosmanpaşa Üniversitesi Ziraat Fakültesi Dergisi, 26 (2): 97-107.

[5] Gümüş E., Şahin N.M., İkiz R., Yılmaz S. 2013. Antalya İlindeki Gökkuşağı Alabalığ1 (Oncorhynchus mykiss) İşletmelerinde Çalışanların Sosyo-Ekonomik Yapılarının İncelenmesi, Ege Üniversitesi Su Ürünleri Dergisi, 30 (4): 161-166.

[6] Aydoğdu S. 2015. Elazığ Yöresinde Gökkuşağı Alabalı̆̆ı (Oncorhynchus mykiss) Yetiştiriciliği Yapan Farklı Kapasitedeki İşletmelerin Yapısal, Teknolojik, Verimlilik ve Çalışmalarının SosyoEkonomik Analizleri, Fırat Üniversitesi, Fen Bilimleri Enstitüsü, Doktora tezi, 152s, Elazığ.

[7] Bromage N., Jones J., Randall C., Thrush M., Davies B., Springate J., Duston J., Barker G. 1992. Broodstock Management, Fecundity, Egg Quality and Timing of Egg Production in the Rainbow Trout (Oncorhynchus mykiss), Aquaculture, 100: 141-166.

[8] Anonim 2017. Su Ürünleri İstatistikleri, Gıda Tarım ve Hayvancılık Bakanlığı, https://www.tarim.gov.tr/sgb/Belgeler/SagMenuVeriler/BSGM.pdf

[9] Aydın A. 2012. Doğu Anadolu ve Akdeniz Bölgelerindeki Alabalık İşletmelerinin Karşılaştırmalı Yapısal ve Ekonomik Analizi, Dokuz Eylül Üniversitesi Sosyal Bilimler Enstitüsü Dergisi, 16 (1): 135-158.

[10] Aras A. 1988. Tarım Muhasebesi, Ege Üniversitesi Ziraat Fakültesi Yayınları No: 486, İzmir. 
[11] Aç1l F., Demirci R. 1984. Tarım Ekonomisi Dersleri, Ankara Üniversitesi Ziraat Fakültesi Yayınlar1 No: 880, Ders Kitabı No: 245, 372s, Ankara.

[12] Yıldız M., Şener E. 2003. Karadeniz Bölgesi’ndeki Gökkuşağı Alabalığı (Oncorhynchus mykiss) ve Deniz Levreği (Dicentrarchus labrax) Yetiştiriciliği Yapan İşletmelerin Yapısal Analizi ve Biyo-Teknolojik Özellikleri, İstanbul Üniversitesi Veteriner Fakültesi Dergisi, 29 (2): 241-252.

[13] Emre Y., Diler İ., Sevgili H., Oskay D.A., Sayın C. 2007. Akdeniz Bölgesi'ndeki Alabalık İşletmelerinin Yapısal Özelliklerinin İncelenmesi (2002-2003), Türk Sucul Yaşam Dergisi, 3-5 (58): 476-489.

[14] Kocaman E.M., Aydın A., Ayık Ö. 2002. Erzurum'da Faaliyet Gösteren Alabalık İşletmelerinin Yapısal ve Ekonomik Analizi, Journal of Fisheries \& AquaticSciences, 19 (3-4): 319-327.

[15] Gümüş E., Şahin N.M. 2015. Antalya İlindeki Gökkuşağı Alabalığı (Oncorhynchus mykiss) İşetmelerinin Kuluçka Faaliyetlerinin Analizi, Biyoloji Bilimleri Araştırma Dergisi (BİBAD), 8 (2): 44-50.

[16] Gümüş E., Şahin N.M., Üstündağ E., Atalay M.A. 2016. Antalya İlindeki Alabalık İşletmelerinin Yapısal Özelliklerin İncelenmesi, Biyoloji Bilimleri Araştırma Dergisi (BİBAD), 9 (1): 33-39.

[17] Doğan K., Yıldız M. 2008. Marmara Bölgesi Gökkuşağı Alabalığı (Oncorhynchus mykiss) İşletmelerinde Çalışanların Sosyo-Ekonomik Analizi, İstanbul Üniversitesi Su Ürünleri Dergisi, 23: $17-27$. 


\section{EK-1: ANKET FORMU}

\section{Yapısal özellikler}

\section{Tesisin adi:}

Sahibinin adı:

Adresi ve mevkii:

Telefon: Faks:

İlçe:

II:

Kuluçkahanenin yetiştiricilik belge numarası:

Kuruluş yılı:

Kuluçkahanenin yerleşim merkezine uzaklığ $1(\mathrm{~km})$ : İlçe: $\quad$ İl:

Yol Durumu (km): $\quad$ Asfalt () Stabilize () Toprak ()

Kuluçkahanenin kurulmuş olduğu arazinin durumu: Vadi arası () Dağ eteği () Açık arazi () Arazinin mülkiyet durumu: Özel mülk () Şahıstan kiralama () Devletten kiralama () diğer () Arazi kira ise kira süresi (Y1l) ve ücreti (TL):

Arazinin alanı $\left(\mathrm{m}^{2}\right)$ :

Kuluçkahane alanı $\left(\mathrm{m}^{2}\right)$ :

Tesiste kullanılan su kaynağı: Yeraltı suyu () Kaynak suyu () Akarsu () Göl-gölet () Diğer ()

Suyun: Çözünmüş $\mathrm{O}_{2}(\mathrm{mg} / \mathrm{L})$, pH, sıcaklık $\left({ }^{\circ} \mathrm{C}\right)$ ve debi $(\mathrm{L} / \mathrm{sn})$ değerleri.

Suyun kuluçkahaneye mesafesi:

Suyun kuluçkahaneye alınış şekli: Boru () Kanal ()

Suyun tesise yeterliliği:

Tesisin kapasitesini arttırmak için uygunluğu:

Periyodik olarak su analizleri yapılıyor mu?

Yıl içerisinde su ile ilgili karşılaşılan problemler: Bulanıklık () Miktar azalması () Diğer ()

Havuzların ana yapı malzemesi: Beton () Toprak () Plastik () Metal ()

Kuluçka dolabı sayısı ve özelliği:

Kuluçka teknesi sayısı ve özelliği: Beton () Fiberglas ()

İşletmenin yapısı: Şahıs () Şirket-Ortaklık) () Kooperatif () Kamu kuruluşu () Diğger ()

Projelendirilmiş kapasite:

Üretim (fiili) kapasitesi:

Kapasite kullanım oranı:

Mevcut havuzların yapısal özellikleri: Beton () Toprak ()

Havuzların niteliği: Yavru () Damızlık () Dinlendirme () Çökeltme ()

Havuzların şekli, genişliği (m), eni (m) ve derinliği (m)

İşletmedeki çalışan personel sayısı:

Personelin yaş durumu:

Personelin cinsiyeti:

Personelin öğrenim durumu:

Personelin görevi:

Personelin iş tecrübesi (yıl):

İşletmedeki iş gücü: Aile iş gücü () Devamlı iş gücü () Geçici iş gücü ()

\section{Biyolojik ve teknik özellikler}

Dişi ve erkek anaç balıkların sayısı, yaşı, ağırlık ve boy değerleri:

Anaç balıkların temin şekli:

Anaç balıklarda sağım sayısı:

Sağım zamanı:

Sağım şekli:

Anaç balıklardan alınan yumurtanın sayısı (adet) ve çapı:

Üretimde kullanılan toplam yumurta sayısı (adet):

Yumurtaları dölleme şekli:

Kuluçkalama aracı:

Döllenmiş yumurtanın gözlenme ve açılma süreleri (gün):

Ortalama kuluçka randımanı (\%):

Sağım sonrası anaçlarda yumurta kontrolü yapılıyor mu?

Sağım öncesi anestezi uygulaması yapılıyor mu?

Anestezik madde ve kullanım oranı: 